\title{
Development of thin, spray-on liner and composite superliner area supports for damage mitigation in blast- and rockburst-induced rock failure events
}

\author{
J. F. Archibald \& P. A. Dirige \\ Department of Mining Engineering, Queen's University, Canada
}

\begin{abstract}
Research has been performed for the Workplace Safety and Insurance Board of Ontario (WSIB) to characterize the capabilities of innovative mining support agents, designated as spray-on lining materials (TSL's), as well as combinations of TSL's and conventional spray supports, for mitigating dynamic failure effects created by simulated rockbursts. The assessment of support capabilities of TSLs and ultra-thin hybrid liner supports (superliners) is novel and constitutes work that is unique in the field of underground excavation support design. This study has been performed to assess the capabilities of TSL and conventional spray-on support systems for preventing rock and support material damage that often results due to rockbursting. In this research, TSL products and superliner combinations of each with ultra-thin shotcrete or fibrecrete layers (at 5 and $3 \mathrm{~cm}$ thicknesses, respectively) have been tested. Support performance was studied using field scale explosive detonation trials to simulate dynamic failure effects that are known to develop during typical rockburst events. Multiple seismic and high speed photographic monitoring techniques were used to provide detailed information concerning rock motion, surface fracturing, ejected fragment motion and support liner survivability characteristics. The results of this study have validated that thin, spray-on linings (TSL's) and variant layer combinations may be as effective as or better than conventional support materials for mitigating rockburst or like damage in highly stressed mine environments.

Keywords: TSLs, spray-on, liners, rockbursts, damage, fracture, mitigation.
\end{abstract}




\section{Introduction}

Research on rapidly deployable, thin spray-on linings (TSL's) has been conducted within the mining industry to promote enhanced underground excavation support capabilities and worker safety in current and future deep mine environments. A variety of different forms of TSLs have been identified and tested by the authors to establish a preliminary database of material performance behaviour, part of which is summarized in Table 1.

Table 1: Typical TSL product characteristics.

\begin{tabular}{|c|l|l|c|c|c|}
\hline $\begin{array}{c}\text { TSL } \\
\text { Product }\end{array}$ & $\begin{array}{c}\text { Mix Type } \\
(1)-\text {-liquid/liquid } \\
(2)-\text { liquid/solid }\end{array}$ & Origin & $\begin{array}{c}\text { Tensile } \\
\text { Strength } \\
(\mathrm{MPa})\end{array}$ & $\begin{array}{c}\% \\
\text { Elongation }\end{array}$ & $\begin{array}{c}\text { Adhesion } \\
\text { Strength } \\
(\mathrm{MPa})\end{array}$ \\
\hline Mineguard & polyurethane (1) & Canada & 15.58 & +100 & 0.56 \\
\hline Rockguard & polyurethane/polyurea (1) & Canada & 11.36 & 86.7 & 0.43 \\
\hline RockWeb & polyurea (1) & Canada & 13.05 & +100 & 0.40 \\
\hline MS1251 & methacrylate/cement (2) & U.S.A. & 2.50 & 65.9 & 0.50 \\
\hline Tekflex W & latex/cement (2) & U.S.A. & 2.01 & +100 & 0.77 \\
\hline Geoflex & Fibre/emulsion (2) & U.S.A. & 0.84 & +100 & 0.39 \\
\hline MS845A & polymer/cement (2) & U.S.A. & 3.23 & 17.6 & 0.58 \\
\hline Rock Safe & polyester (1) & U.S.A. & 19.73 & 9.6 & 0.61 \\
\hline TTC & polyurea (1) & Canada & 6.23 & +100 & 0.54 \\
\hline TTC Web & polyurea (1) & Canada & 8.92 & 36.2 & 0.50 \\
\hline
\end{tabular}

\section{TSL field testing and support characterization}

Under research sponsorship of the Workplace Safety and Insurance Board of Ontario (WSIB), TSLs have demonstrated significant support benefit, particularly for mitigation of rockburst damage as created by large scale blasting trials Archibald and Katsabanis [1]. A range of area support materials has been studied for damage mitigation effectiveness, including conventional area supports (bolts-and-mesh, shotcrete and fibrecrete), thin $(2-5 \mathrm{~mm})$, stand-alone TSL agents, and combinations of both (Superliners or SLs). Application of flexible support membranes may offer potential for preventing rock degradation and structural failure of excavations. TSL and conventional area supports are used to mobilize and conserve the inherent rock mass strength immediately about excavations. Environmental factors, such as mine-induced stress, can induce rock failure susceptibility ranging between gradual to highly dynamic (rockbursting). In post-yield loading, maintenance of rock residual strength requires that confinement be provided for support structures subjected to potentially large deformations.

Flexible spray-on linings, unlike stiffer shotcrete, are designed to provide support over substantial rock deformations so that fractured rock, on or within excavation surfaces, can be held interlocked and frictional strength reinforcement continuously generated. In post-yield failure, liner reaction pressure can mobilize internal frictional resistance and provide some measure of residual strength enhancement Archibald and Katsabanis [2]. The flexible nature of TSLs 
that permits rock structures to continuously deform without rupturing may ultimately enhance pillar softening and sustain low stiffness behaviour, allowing supports to continuously absorb strain energy while maintaining stable support resistance. Large-scale blast trials, as physical analogues to rockbursting, have been used to assess the effectiveness of TSLs and conventional support agents for providing effective rock reinforcement, mitigating dynamic rock ejection and minimizing support media damage. In field testing, a total of eighty-four separate blast trials were conducted using surface rock reinforcement ranging between conventional media, such as rockbolts, bolts-and-mesh, shotcrete and fibrecrete, and TSL media, used stand-alone or when combined with rockbolts, bolts-andmesh, shotcrete or fibrecrete.

\subsection{Blast site investigation}

The region selected for field experimentation was located within an extensive zone of limestone outcrop that was visually indicated to be highly homogeneous and largely unfractured. The extensive occurrence and consistent visual quality of the strong, brittle limestone provided highly uniform rock conditions between successive sites. The outcrop was also sampled by diamond drilling, and core sample analysis, through compression testing, was used to provide additional assessment of the uniformity of rock mass character across the entire surface extent of the proposed test area. The locations of proposed blasting test sites over the mapped outcrop zone are illustrated in Figure 1.

Based upon results illustrated in Figure 1, a zone of outcrop exposure exhibiting highly consistent rock mechanical behaviour was identified to trend southwest to northeast over the proposed area of study. A total of ninety-four potential test sites, each at $4 \mathrm{~m}$ by $5 \mathrm{~m}$ in plan area, were identified, cleared and subjected to support material installation, as shown in Figure 2. Identical blast trials were conducted at all test sites by loading centrally placed, $63.5 \mathrm{~mm}$ diameter by $2.38 \mathrm{~m}$ long blastholes at each site with $1.5 \mathrm{~kg}$ of a commercial emulsion explosive (Magnafrac Plus HW Emulsion). Explosive materials were placed using subgrade and stemming depths of $0.56 \mathrm{~m}$ and $1.22 \mathrm{~m}$, respectively, in each blasthole. A consistent depth of charge burial and weight of charge was adopted that was sufficient to induce surface heave or cratering capable of generating conditions of rock movement (shown in Figure 3) similar to those encountered underground during actual rockburst occurrences Tannant et al. [3]. By insuring that uniform rock and blast source energy conditions existed for each trial the capabilities of different surface cover/liner systems to mitigate resultant rock damage effects could be reliably compared. During blasting, vertical ground velocity, vertical movement (heave) and rock ejection conditions were measured using near- and far-field vibration sensors and a high speed (500 fps) digital video camera. Ground vibration data was monitored using Instantel Inc. Minimate and Engineering Seismology Group Canada Inc. (ESG) Paladin seismic recording systems. Post-blast damage, including ground fracturing within rock and surface support cover materials, was assessed through analyses of digital blast images and direct measurement of site conditions. Baseline blast testing on unsupported rock sites (Figure 4) was used to establish a minimum site 
vertical wave velocity condition of $2500 \mathrm{~mm} / \mathrm{s}$ in the frequency range between $25-500 \mathrm{~Hz}$, as is typically produced by in-situ rockburst events Urbancic [4].

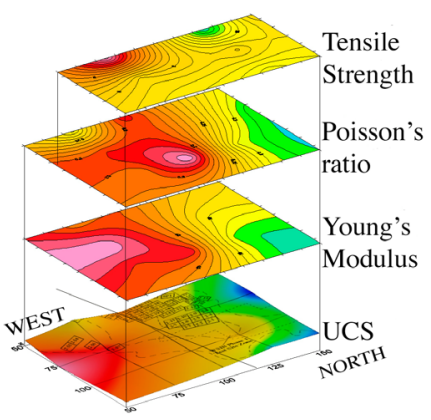

(a)

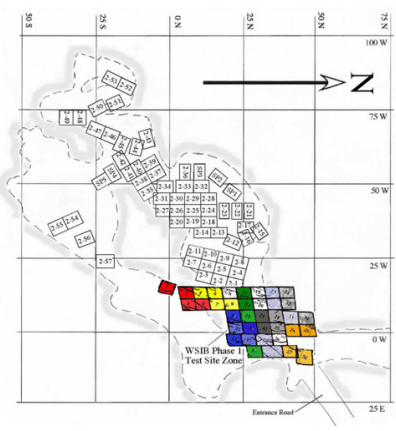

(b)

Figure 1: (a) Test zone rock parametric conditions and (b) plan layout of blast test sites for rockburst simulation trials.
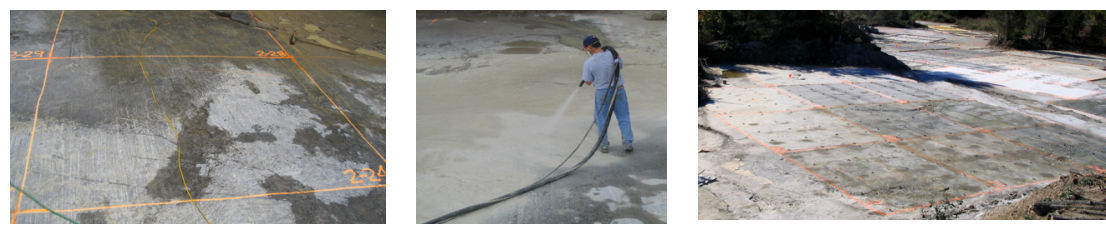

Figure 2: $\quad$ Views of cleared outcrop, TSL installation and prepared sites.

In subsequent supported-site tests, for 480 ground vibration measurements, an extrapolated vertical velocity component of ground motion was found to approximate $20.3 \mathrm{~m} / \mathrm{s}$ that well exceeds the minimum damage criterion of 2.0 $\mathrm{m} / \mathrm{s}$ normally utilized to characterize rockburst events Urbancic [4], Espley et al. [5], Persson et al. [6].

\subsection{Blast damage assessment}

Post-blast damage assessment included evaluation of cover agent fragmentation or intactness (if visible), the incidence of material tear-through, the ability of cover agents to maintain tight contact with underlying rock surfaces, and the capability of cover agents to restrict rock fragment travel or expulsion away from the outcrop surface during the detonation (i.e.- simulated rockbursting) process. A range of typical site performance and damage characteristics for unsupported and surface-reinforced sites is summarized in Table 2. All unsupported and supported sites exhibited relatively similar surface heave and heave velocity behaviour, with vertical surface heave and heave velocities generally ranging between $3.8-6.8 \mathrm{~cm}$ and $5.2-7.1 \mathrm{~m} / \mathrm{s}$ respectively. 


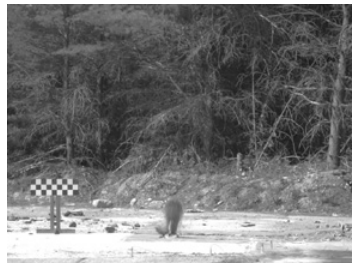

$8 \mathrm{~ms}$

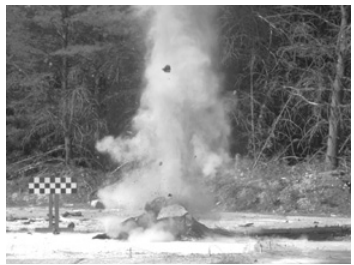

$80 \mathrm{~ms}$

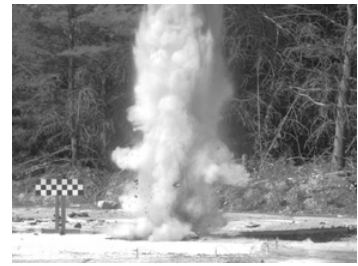

$32 \mathrm{~ms}$

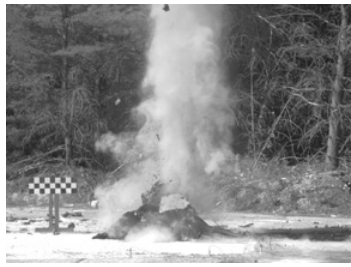

$104 \mathrm{~ms}$

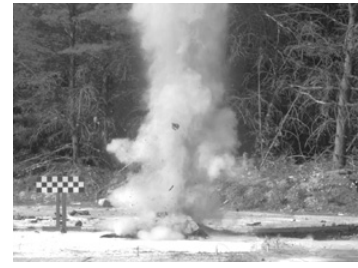

$56 \mathrm{~ms}$

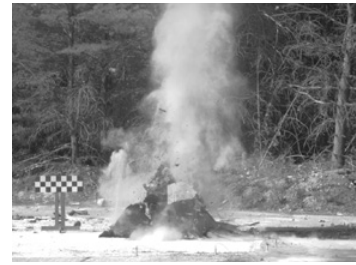

$128 \mathrm{~ms}$

Figure 3: Unsupported site ground motion versus time after blast detonation.
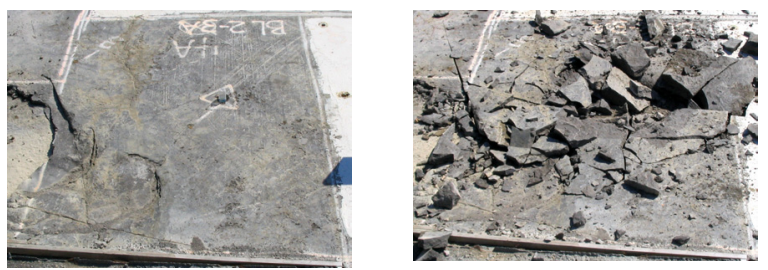

Figure 4: Pre- and post-blast views of unsupported baseline site.

Significant differences were, however, noted in developed site damage effects where no support, conventional media support and TSL media support was provided. Site and support media damage that was observed during post-blast examination ranged between extensive (for no support or at sites supported by conventional media) to minor (for sites using conventional media such as $10 \mathrm{~cm}$ thick shotcrete layers and TSL media in stand-alone and composite layers), as illustrated in the composite site views shown in Figure 5.

Site examination verified that significant rock damage can result following simulated rockburst exposure where no support (baseline case) or conventional rockbolt or bolt-and-mesh support is placed. At such sites, rockbolt heave, rupture of the mesh component of bolt-and-mesh media and ejection of large quantities of rock fragments were induced by blasting. Where sites were reinforced using stand-alone TSL products, conventional area covers (such as 10 $\mathrm{cm}$ shotcrete or $6.5 \mathrm{~cm}$ fibrecrete layers), or combinations of (TSLs+bolts), (TSLs+bolts-and-mesh), (TSLs+shotcrete) and (TSLs+fibrcrete), the great majority exhibited significantly less support cover damage and rock ejection following blasting than did sites supported using conventional media. 
Table 2: Damage characteristics of typical unsupported and supported blast sites.

\begin{tabular}{|c|c|c|c|c|}
\hline Support Material & $\begin{array}{c}\text { Layer } \\
\text { Thickness }(\mathrm{cm})\end{array}$ & $\begin{array}{c}\text { Number of } \\
\text { Fractures }\end{array}$ & $\begin{array}{c}\text { Fracture } \\
\text { Length }(\mathrm{m})\end{array}$ & $\begin{array}{c}\text { Damage } \\
\text { Radius }(\mathrm{m})\end{array}$ \\
\hline No Support & --- & 9 & 1.59 & 1.55 \\
\hline Bolts Only & --- & 6 & 2 & 1.04 \\
\hline Bolts \& Mesh (B\&M) & --- & 6 & 1.57 & 1.09 \\
\hline Shotcrete & 10 & 10 & 1.56 & 0 \\
\hline Fibrecrete & 6.5 & 6 & 1.88 & 0.61 \\
\hline RockWeb Only & 0.43 & 7 & 0.60 & 0.57 \\
\hline Geoflex Only & 0.20 & 4 & 0.78 & 0.12 \\
\hline Tekflex W + Bolts & 0.43 & 6 & 0.95 & 0.25 \\
\hline RockWeb + (B\&M) & 0.43 & 4 & 1.59 & Not visible \\
\hline TTC Web + Fibrecrete & $0.30 / 3.3$ & 5 & 1.37 & 0.71 \\
\hline Geoflex + Shotcrete & $0.20 / 5.0$ & 9 & 1.05 & 0.11 \\
\hline TTC Web + Shotcrete & $0.38 / 5.0$ & 9 & 1.01 & 0.13 \\
\hline
\end{tabular}

At baseline sites, the average number of new fractures created, average crack length generated and average radius of the zone of damage located immediately about blastholes were measured to approximate $9,1.59 \mathrm{~m}$ and $1.55 \mathrm{~m}$ respectively. For tests in which TSL stand-alone support was utilized, the average number of new fractures induced by blasting ranged between 2-6 per site, this being 33 to $78 \%$ fewer than for the baseline (unsupported) case. Similarly, TSL-only media realized average propagated crack lengths through the support materials ranging between $0.12-0.85 \mathrm{~m}$, these being significantly less than the average crack length measured to develop for unsupported rock test cases. The average radius of the localized failure zone immediately about blastholes was also found to be significantly larger (at an average of $1.55 \mathrm{~m}$ ) where rock remained unsupported relative to TSL-supported sites (which displaying average radii ranging between 0.13-0.57 m). A minimum 70\% reduction of the rockburst-induced fracture zone was realized through application of stand-alone TSL restraint.

\subsection{Site damage mitigation comparison}

Damage measurements at sites reinforced using conventional rockbolts and (TSL+rockbolt) combinations indicate that significant reductions in both the frequency and length of fractures generated within the rock and support media can be made through the added application of TSL materials (Figure 6). At a small number of sites where more brittle, cementitious-type TSL products (such as MS1251) were utilized, a higher frequency of fracture occurrence was observed. However, the primary benefit realized by the application of innovative TSL reinforcement can be illustrated by the capacity of such supports to restrict the extent of site damage created by simulated rockbursts, as characterized by the damage zone radius parameter. 


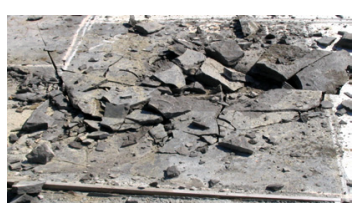

unsupported

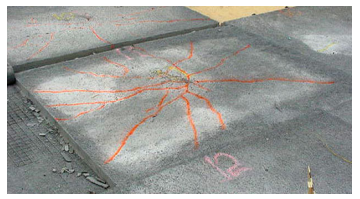

$10 \mathrm{~cm}$ shotcrete

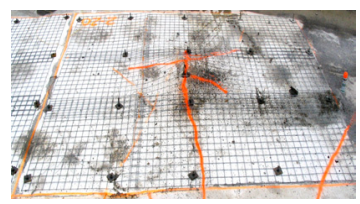

Geoflex TSL + B\&M

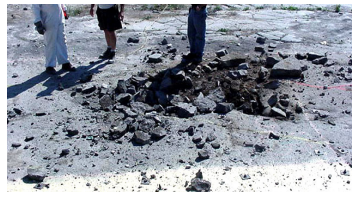

rockbolts-only

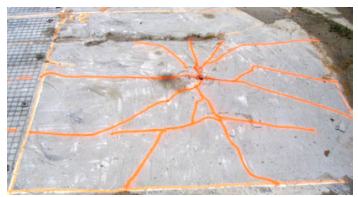

Tekflex W TSL only

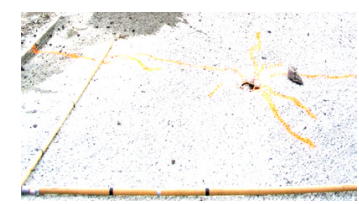

TTC Web + shotcrete

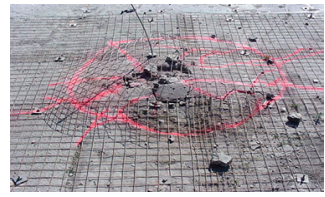

bolts-and-mesh only

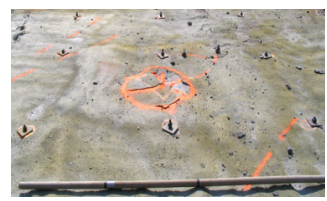

RockWeb TSL + bolts

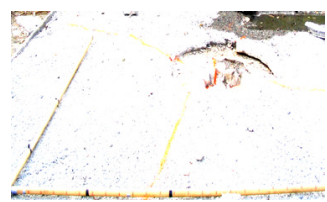

MS845A +fibrecrete

Figure 5: $\quad$ Post-blast damage conditions at typical blast sites.
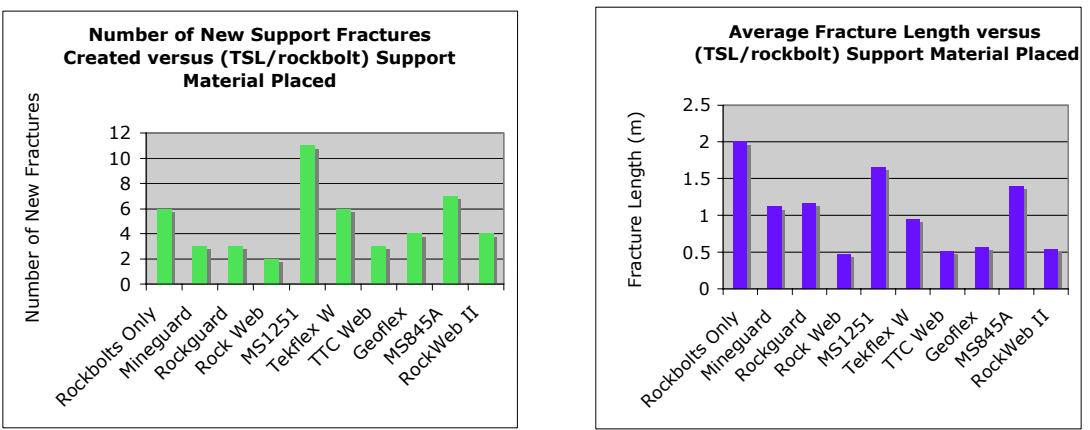

Figure 6: Fracture damage at rockbolt-reinforced sites.

For the entire range of different support measures applied, including combinations of TSLs and thin shotcrete or fibrecrete top layers, post-blast measurements have shown that significantly reduced radial damage zones exist about blastholes at sites reinforced using TSLs in stand alone or combined fashion relative to all sites reinforced using only conventional support media. A partial summary of radial damage zone results is provided in Figure 7 for TSLand $(\mathrm{TSL}+$ bolt)-supported site test measurements. In terms of the radial zone of fracturing generated by blasting, stand-alone TSL media (illustrated in Figure 
8) exhibited excellent fracture resistance and yielded reductions in the size of the damage influence zone by a minimum of $60 \%$ relative to unsupported rock sites, by a minimum of $33-50 \%$ relative to rockbolt-only supported sites, and by $50 \%$ or more relative to conventional bolt-and-mesh supported sites.
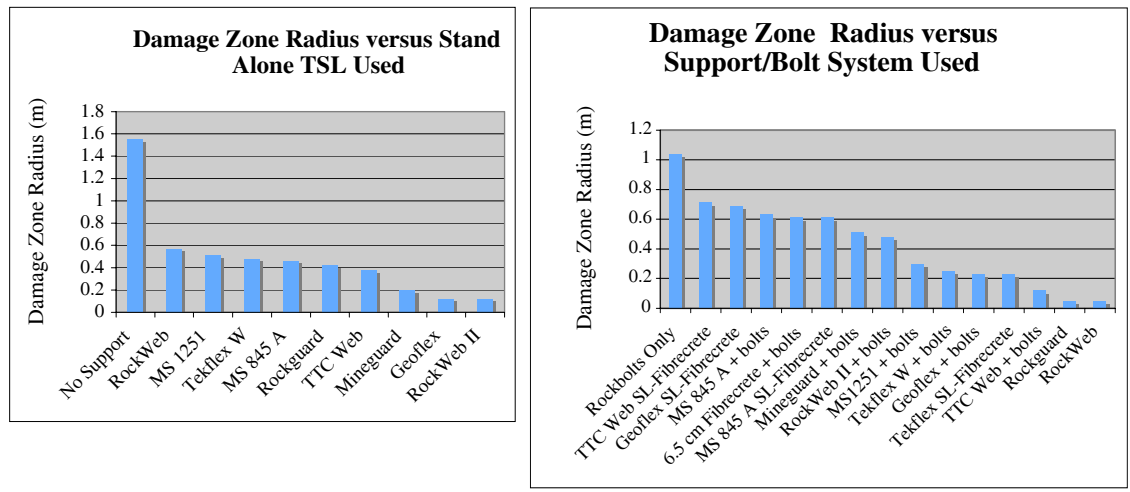

Figure 7: Summary of damage zone radius conditions for typical support media.

Where $10 \mathrm{~cm}$ thick conventional shotcrete layers were used for area support, only limited damage was noted immediately about blastholes, accompanied by generation of extension fractures within and through the shotcrete layers. Combinations of TSLs and $5 \mathrm{~cm}$ thin shotcrete top layers experienced similar support layer effects, with only very localized support damage being generated immediately about each blasthole site within and through the thinner (SLshotcrete) layers. The radial zone of damage created by blasting was larger and more pronounced in $5 \mathrm{~cm}$ thick (SL-shotcrete) materials than in conventional 10 $\mathrm{cm}$ thick shotcrete materials. The damage zone induced within (SL-shotcrete) layers averaged $0.24 \mathrm{~m}$ for all TSL materials used, suggesting that thin layer (SL-shotcrete) applications offer generally equivalent support benefit, in terms of rockburst damage suppression effectiveness, when applied in similar fashion to $10 \mathrm{~cm}$ thick layers of conventional shotcrete media.

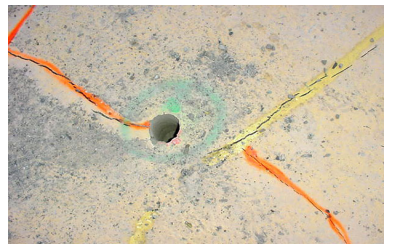

Rockguard TSL

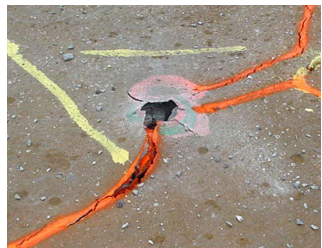

RockWeb TSL

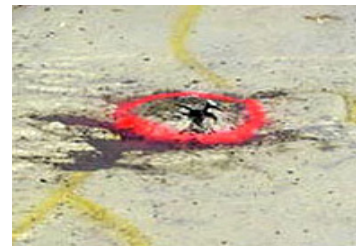

Mineguard TSL

Figure 8: $\quad$ Limited radial damage about blastholes for TSL-only supported sites. 
Testing of $6.5 \mathrm{~cm}$ thick, stand-alone fibrecrete layers yielded considerable layer damage consisting of localized fracturing about blastholes and, in one case, release of fibrecrete from the rock surface for which support was being provided. Where $3.3 \mathrm{~cm}$ thick (SL-fibrecrete) support was utilized, similar layer damage occurred with consequent shattering of the fibrecrete top layer and its release from the underlying TSL layers immediately above the rock surface. Underlying TSL materials, in most cases, were observed to maintain strong adhesion contact with rock surfaces. For (SL-fibrecrete)-supported sites, radial zones of damage ranging between $0.61-0.71 \mathrm{~m}$ were measured after blasting, with only one SLfibrecrete material (Tekflex $\mathrm{W}$-based) yielding superior radial damage mitigation $(0.23 \mathrm{~m})$ relative to conventional fibrecrete layer materials (that averaged $0.50 \mathrm{~m}$ radial damage).

\section{Conclusions}

A range of TSL materials, of varying chemical and physical composition, have been developed in efforts to create lower cost, environmentally safe materials suitable for underground installation under a wide variety of site conditions. Most TSL products can be identified as having rapid set, tenacious adhesion, high deformability, high tensile strength and beneficial support capabilities.

Characterization work has been completed on a total of eleven TSL products as potential mine support agents. Additionally, field blast testing was conducted to provide comprehensive assessment of support responses and damage mitigation capabilities of a variety of conventional and TSL area support materials when subjected to dynamic failure under conditions representative of in-situ rockburst impacts. In site trials where no support (baseline case) or only conventional support techniques were applied (rockbolts or bolts-and-mesh), considerable damage to rock surfaces and support media was consistently developed. Significant numbers of rock fragments were ejected from rock surfaces in every trial where no support or conventional support was applied. Damage effects observed included significant rock fracturing, large scale ejection of rock fragments in excess of $10 \mathrm{~cm}$ diameter, and failure of support media adjacent to blastholes (rockbolt ejection and/or mesh displacement and bending). Sites reinforced using conventional support materials suffered characteristically large heave zone radius, crack numbers and crack length generation. When viewed in combination with an inability to restrict rock fragment ejection from the sites of detonation, this provides indication that conventional support media are generally ineffective for mitigating rockburst (or blast-induced) damage.

With few exceptions, the application of TSL materials onto rock, in standalone fashion or in combination with conventional area support media, has been shown to significantly reduce apparent surface damage effects caused by rockburst simulation relative to cases where the rock is left unsupported. The ability of the majority of TSL compositions to resist fracture growth, limit the extent of propagating fractures, and maintain liner integrity while strongly adhering to rock surfaces that they are intended to reinforce, indicates that they 
possess a beneficial and enhanced capacity to resist rock ejection and movement away from burst-affected surfaces, especially when viewed relative to cases where no rock support is provided. Based upon mining field support trials, the majority of TSL products evaluated have been shown to generate support performance equivalent to that of bolts and welded wire mesh, and thin shotcrete linings. Support benefits have also been exhibited in terms of spray-on liner capabilities to enhance rock strength and strain energy storage capacities. Where installations are planned in areas of high-energy release or rockburst-prone mine environments, these liner benefits may well serve to enhance worker protection against possible hazards by constraining falls of ground or dynamic rock movement. Rockburst simulation tests have identified that TSL materials may be potentially very effective in mitigating rockburst damage to both the support materials and rock surfaces onto which they are placed. This research has validated the assumption that TSL supports may be equivalent to or substantially better than conventional area support methods for providing safe, capable and sustainable support in the event of dynamic rock failure. The entire range of TSL types evaluated has demonstrated an ability to deform substantially and to therefore constrain fragment or loose rock ejection created by energetic spalling. By so doing, these tenaciously-adhering, thin layer, deformable cover materials have also demonstrated an ability to mitigate damage often seen to result when catastrophic unsupported rock failure occurs.

\section{References}

[1] Archibald, J. F. and P. T. Katsabanis, P. T. Workplace Safety and Insurance Board of Ontario (WSIB) Report \#00 007- Assessing acceptance criteria for and capabilities of liners for mitigating ground falls. Technical Report, October, 2002.

[2] Archibald, J. F. and Katsabanis, P. T. Workplace Safety and Insurance Board of Ontario (WSIB) Report \#03 010- Ground fall mitigation capability and enhanced liner testing for rockburst susceptibility of rock liners. Technical Report, October, 2005.

[3] Tannant, D. D., McDowell, G.M., Brummer, R. K. and Kaiser, P. K. Ejection velocities measured during a rockburst simulation experiment. International Conference on Rockbursts and Seismicity in Mines (Balkema Publishing, Rotterdam, Netherlands), pp. 129-133, 1993.

[4] Urbancic, T. Personal communication. Engineering Seismology Group Canada Inc. (ESG), Kingston, Ontario, Canada, 2001.

[5] Espley, S. J., O’Donnell, J. D., Thibodeau, D. and Paradis-Sokoloski. P. Investigation into the replacement of conventional support with spray-on liners. CIM Bulletin, V. 89, No. 1001, 135-143, 1996.

[6] Persson, P., R. Holmberg, R. and J. Lee. 1992. Rock Blasting and Explosives Engineering. London; CRC Press Inc. 